\title{
Etnodesarrollo y gestión territorial en contextos turísticos patagónicos
}

Ethnodevelopment and territorial management in patagonian tourist contexts

\section{Etnodesenvolvimento e gestão territorial nos contextos turísticos patagônicos}

\section{Marcelo Impemba ${ }^{1}$}

\begin{abstract}
Recibido: 12 de abril de 2020
Aprobado: 30 de noviembre de 2020

Publicado: 12 de enero de 2021

Cómo citar este artículo:

Impemba, M. (2021). Etnodesarrollo y gestión territorial en contextos turísticos patagónicos. Cooperativismo \& Desarrollo, 29(119), 1-15. doi: https://doi.org/10.16925/2382-4220.2021.01.09
\end{abstract} Aires. Profesor e investigador de la Facultad de Turismo de la Universidad Nacional del Comahue, Argentina.

Correo electrónico: impemba@smandes.com.ar ORCID: https://orcid.org/0000-0002-2217-4736 


\section{Resumen}

Los temas y contenidos expresados en este artículo son el resultado de diferentes proyectos de investigación y extensión universitaria, en los cuales se analizó el desarrollo turístico y su incidencia sociocultural y económica en comunidades mapuche de la región andina patagónica de Argentina. Abordar el turismo teniendo en cuenta su contexto espacial e histórico, en relación con las comunidades indígenas, representa un amplio campo de investigación sobre aquellos cambios en las condiciones ambientales, territoriales y sus prácticas productivas. Entre los ejes que han guiado el trabajo de campo, se pueden destacar el estudio de sus acciones reivindicativas, las transformaciones territoriales, y las representaciones y estigmatizaciones del resto de la sociedad, desde la perspectiva del etnodesarrollo turístico.

Palabras clave: comunidades mapuche, territorio, etnodesarrollo turístico, relaciones interétnicas, campo turístico.

\section{Descriptores:}

Z32 Turismo y desarrollo

03 Investigación y desarrollo

Z1 Economía cultural, Sociología económica, Antropología económica

\section{Abstract}

Themes and content expressed in the present work are the result of different research projects and university extension programs, in which they have addressed the development of tourism and its socio-cultural and economic impact on Mapuche communities of the region andina patagónica of Argentina.

To approach tourism, space and historically contextualized in relation to indigenous communities, represents a vast field of research on those changes in environmental, territorial and their productive practices conditions. Among the axles that have guided the field work, you can highlight the study of their vindictive actions, the territorial changes, and the representations and stigmatization of the rest of society, from the perspective of the ethnodevelopment of tourism.

Keywords: Mapuche communities, territory, tourist development, inter-ethnic relations, tourist field.

\section{Resumo}

Os temas e conteúdos expostos no presente trabalho são o resultado de diferentes projetos de pesquisa e extensão universitária, aos quais foram abordados o desenvolvimento turístico e sua incidência sociocultural e econômica em comunidades mapuche da região andina patagônica do Argentina.

Abordar o turismo no seu contexto espacial e histórico em relação às comunidades indígenas representa um amplo campo de investigação sobre aquelas mudanças nas condições ambientais, territoriais e suas práticas produtivas.

Entre os eixos que orientaram o trabalho de campo destacam-se o estudo de suas ações reivindicativas, alterações territoriais, e as representações e estigmatizações do resto da sociedade desde uma perspectiva do etnodesenvolvimento turístico.

Palavras chave: Comunidades mapuche, territorio, Etnodesenvolvimento turístico, relações interéticas, campo turístico. 


\section{Introducción a la visión social sobre el desarrollo turístico}

Un enfoque crítico sobre el turismo, que considere, entre otros aspectos, las consecuencias y transformaciones territoriales del medio rural desde una perspectiva étnica, representa una necesidad y un desafío epistemológico y académico. También es una oportunidad, en medio de la pandemia del Covid-19, para visibilizar y exponer las fuertes contradicciones en el campo turístico, siendo estos cuestionamientos que recaen sobre el modelo de gestión de esta actividad socioeconómica.

En ese sentido, se trata de superar la simplificación que supone encontrar en una relación de causa y efecto, los cambios generados por el desarrollo del turismo y sus resultados inmediatos y directos. Así, son múltiples los factores socioculturales y territoriales que influyen en una población rural con actividad turística. Estas mutaciones, mediadas por relaciones interétnicas, no son exclusivas del turismo y hunden sus raíces en factores sociales e históricos de un contexto determinado, en el cual el turismo representa un instrumento que complejiza aún más la realidad intervenida. La inserción de la actividad turística en territorios rurales indígenas es una manifestación socioeconómica reciente en un territorio en disputa y conflicto. Las consecuencias generadas por esta actividad socioeconómica ya se perciben, como también los cambios producidos en las prácticas productivas y estructuras organizacionales, pues el turismo incorpora, en las unidades domésticas o comunitarias, prácticas creadas y sostenidas desde un capitalismo tardío en estos contextos rurales y étnicos, implantadas en una realidad basada históricamente en una economía de subsistencia (Impemba y Maragliano, 2019).

En ese orden de ideas, se requiere de una exploración que proceda de un trabajo de campo continuo, y permita acceder y analizar en forma directa el contexto y las estructuras sociales en las que se desarrollan las propias prácticas derivadas de la intervención profesional, superando lo estrictamente técnico para internarnos en lo político e ideológico.

En las últimas dos décadas nuestro interés ha sido estudiar, mediante diversos proyectos de investigación universitaria aplicada', cómo se adaptan y redefinen las relaciones interétnicas, en particular en las comunidades mapuche, y entre ellas las formas que adoptan las estrategias de intercambio en contextos mediatizados por el campo turístico de la región norte andina patagónica. El trabajo de campo desarrollado en los distintos proyectos nos ha permitido abordar diversas dimensiones de

1 Como también de desarrollo tecnológico y social (pdts), extensión y voluntariado universitario. 
análisis, por ejemplo: los procesos de reterritorialización y transformaciones sociales, que se inscriben a partir de la decisión política de incorporar al turismo en economías de subsistencia y fuerte dependencia estatal. También, desde un abordaje antropológico, hemos podido estudiar a las poblaciones mapuche en las áreas protegidas nacionales, con el fin de evidenciar las limitaciones, los conflictos y las reivindicaciones que han tenido en relación con sectores estatales dominantes (Valverde, 2010; Balazote, 2006; Impemba, 2017).

Al poner sobre la mesa modelos de desarrollo impuestos, nos preguntamos si estos representan una extensión de las relaciones de subordinación y sometimiento, desde factores de poder públicos, privados o ambos en forma vinculante. Ante la falta de alternativas en estas regiones de frontera, alejadas de los centros urbanos, el turismo representa el ingreso al desarrollo. Es símbolo de bienestar y fuente de ingresos. En contraposición, encarna un importante factor de reconversión de su economía de base.

Las representaciones que se derivan de una interculturalidad incompleta inciden en la construcción social de las poblaciones indígenas acerca del turismo. Esta se sustenta en la idea de progreso económico, promovida y sostenida desde las dimensiones "ocultas" del discurso político hegemónico, desconociendo, en la mayoría de los casos, las implicaciones sociales y culturales que condicionan las prácticas cotidianas de las poblaciones involucradas directa e indirectamente y su incidencia en sus estructuras comunitarias, organizaciones etnopolíticas y domésticas familiares. Todo este proceso se ha acelerado como consecuencia del avance de políticas públicas neoliberales, que se ha venido consolidando en toda Latinoamérica; esto ha traído consigo un proceso de endeudamiento que lleva inexorablemente al ajuste y recesión, regresión en conquistas sociales, la implementación de un discurso dominante y globalizado que conlleva formas represivas contemporáneas (Coraggio, 2007).

En el caso específico de los espacios sociales del norte de la región andina patagónica, han sido un escenario propicio para el denominado extractivismo turístico, reflejando una creciente concentración productiva, con la apropiación de territorios y del trabajo de la población indígena y campesina, entre otros. Como lo expresa Acosta (2011), el extractivismo en los hechos ha sido un mecanismo de "saqueo y apropiación colonial y neocolonial" (p. 84). Un extractivismo que, con diferentes variantes, en el transcurso de los últimos cincuenta años ha promovido la explotación de las materias primas y los recursos, "indispensables para el desarrollo industrial y el bienestar del Norte global. Y se lo ha hecho sin importar la sustentabilidad de los proyectos extractivistas, así como tampoco el agotamiento de los recursos" (p. 86). Las consecuencias han sido el surgimiento de territorios en disputa, fraccionados y 
privatizados; pero también las redefiniciones de configuraciones identitarias, expresadas en las tensiones del uso y acceso a la tierra, junto con la propiedad cultural de sus recursos.

\section{Un análisis al modelo desarrollista en contextos interétnicos}

En el contexto abordado en este trabajo, el turismo se ha expandido sobre un territorio compartido con comunidades originarias, reconocidas tanto por la Constitución Nacional Argentina como provinciales. Estas comunidades han sufrido por más de 120 años los estigmas derivados de la autodenominada Campaña del Desierto², emprendida por el Estado Nacional y los terratenientes de la Pampa Húmeda sobre las poblaciones libres en la Norpatagonia argentina a fines del siglo XIX.

Como resultado de la apropiación y reparto de los territorios patagónicos por parte del Estado Nacional, de las sucesivas campañas militares a fines del siglo XIX, y luego (entrado el siglo Xx) por parte de Parques Nacionales ${ }^{3}$, para consolidar la "estatalidad" en áreas de frontera se les asignó a las poblaciones mapuche que los habitaban con anterioridad a la llegada del ejército, Parques y los colonos, aquellos espacios marginales que quedaron sobrantes de una desigual distribución, tanto para el asentamiento de las familias como para el desarrollo de sus actividades productivas de subsistencia (Díaz, 2002).

En la segunda mitad del siglo xx, la intervención estatal se hizo más sostenida, mediante la implementación de políticas públicas de conservación y de promoción turística, a través de la Administración General de Parques Nacionales (denominada originalmente Dirección de Parques Nacionales). Esta institución diseñó un turismo

2 A fines del siglo XIX, durante el proceso de consolidación del Estado Nación Argentino, se llevaron a cabo acciones militares contra la población mapuche con el objetivo de lograr su desplazamiento de las áreas de las cuencas de los ríos Negro y Neuquén, ubicados en el norte de la región patagónica. La importancia económica de estas campañas militares fue muy significativa, dado que más de 60 millones de hectáreas pasaron a ser controladas por el gobierno de Buenos Aires. Desde 1876, hasta la finalización del siglo XIX, distintas administraciones nacionales entregaron más de las dos terceras partes de las tierras enajenadas a un número muy reducido de personas. La incorporación de los territorios indígenas a la esfera de control estatal trajo como consecuencia inmediata la privatización y concentración de importantes extensiones de tierra.

3 La ocupación efectiva en la región andino-patagónica se completó y reforzó con la radicación y establecimiento de la Administración de Parques Nacionales (APN) en la década de 1930. Las administraciones de los Parques Nacionales definieron, bajo el ideario conservacionista, su función geopolítica que completaba el proceso iniciado con la Campaña del Desierto, en la medida en que hacen efectiva la ocupación de zonas de frontera, facilitando el control militar de los límites internacionales y la dominación de los pobladores originarios. 
selectivo, destinado a "amigos" de la oligarquía porteña, de quien fuera su primer presidente Exequiel Bustillo. Se va consolidando un imaginario de postales europeas en plena Patagonia argentina. San Carlos de Bariloche ${ }^{4}$ comienza a promocionarse como "la Suiza argentina"; Maragliano (2010) afirma que esta zona nació con la idealización y construcción de esta imagen y la elaboración de un programa atractivo para las clases dominantes, turistas internacionales o inversores de la "elite" porteña, de tal forma que se sintieran vacacionando en Europa.

Al mismo tiempo, se fue produciendo la "invisibilidad" del otro. En la construcción de una nacionalidad hegemónica que se estaba consolidando, los pobladores mapuche pasaron a ser negados u ocultados en contextos de frontera. Luego, con el devenir en una región turística con una impronta "europea", lo indígena comienza a formar parte como un elemento más del paisaje, rasgos de tipo folclórico que complementaban la exotización de la oferta turística. Como grupo étnico y colectivo social pleno de derechos, fueron ignorados también por los integrantes de la propia superestructura turística (Balazote, 2006).

Hacia finales del siglo XX, la respuesta a estas prácticas de parte de las poblaciones mapuche fue la lucha por el pleno reconocimiento de sus derechos. Un sector social invisibilizado y sometido, los "otros invisibles", disputaban el poder público a los privados, la apropiación de sus otrora territorios, y la gestión de los sus recursos, incluida la renta turística por su explotación (Impemba, 2013).

Contrario a lo que podría pensarse, la invisibilidad de la población mapuche, mediatizada por el campo turístico, depende entonces de las dimensiones y características de la disputa económica y simbólica en juego. Con su reposicionamiento etnopolítico y social desde finales del siglo pasado, las comunidades indígenas (en nuestro caso el pueblo mapuche) han obtenido una mayor presencia y reconocimiento reivindicativo en lo territorial-cultural, y una impensada visibilización como consecuencia de la expansión turística sobre su territorio y la conflictividad resultante.

A pesar del aprovechamiento turístico de la cultura y cosmovisión mapuche, las formas masificadas del turismo niegan la condición de otredad a sus integrantes como sujetos sociales y cultural contemporáneos. En contextos especializados en turismo, como lo es el norte de la región andina patagónica denominada turísticamente Corredor de los Lagos ${ }^{5}$, se reproducen estereotipos y prejuicios respecto a este colec-

4 Proyectada en primer término como ciudad agroindustrial, luego convertida en el principal destino turístico de toda la Patagonia argentina.

5 Región turística andina patagónica identificada por los Parques Nacionales Lanín, Arrayanes y Nahuel Huapi, que abarca las localidades turísticas de Villa Pehuenia, Aluminé, Junín de los Andes, San Martín de los Andes, Villa Traful, Villa La Angostura y S. C. de Bariloche. 
tivo humano, que se hacen visibles en momentos de tensión ante reposicionamientos étnicos e identitarios de base territorial (toma de tierras o cortes de ruta).

Esta situación nos lleva, necesariamente, a replantear el discurso y el modelo de desarrollo que se ha consolidado en los últimos 70 años, que además se ha trasladado al turismo. Según Viola (2000), el discurso utilizado por el modelo de desarrollo se esgrime como un descriptor de la realidad desde un lenguaje objetivo. Este lenguaje se puede aplicar en diferentes realidades, independientes de su finalidad, interés político o enfoque ideológico. En otras palabras, bajo una lógica estandarizada, las mismas lógicas de desarrollo pueden aplicarse en contextos diversos, abstrayendo las problemáticas de su marco político y cultural, para reformularlas como problemas técnicos y proponer, por ende, soluciones neutrales.

En su interior se interrelacionan tanto el conocimiento, desde donde se construyen conceptos y teorías; como también las relaciones de poder que regulan sus prácticas y, las formas concretas que adopta dicho discurso en los diferentes ámbitos de aplicación, abstrayendo los problemas de su marco político y cultural, para formularlos como problemas técnicos, y proponer soluciones neutrales. (Viola, 2000, p. 22)

Este marco del desarrollo, contradictoriamente, muestra su verdadero rostro con el aumento en los niveles de pobreza y desocupación; con lo cual sostiene y refuerza las relaciones de poder que han fomentado la concentración económica y una producción centralizada a gran escala, en contra de una descentralización de la producción a escala local (Manzanal, 2010).

Solo desde una cierta perspectiva occidental, como sostiene Escobar (2007), este discurso en un sistema mundial representa su dominio sobre el Tercer Mundo y tiene profundos efectos de tipo político, económico y cultural, lo que involucra la producción social del espacio. "A pesar de los cambios recientes en esta geopolítica -el descentramiento del mundo, la desaparición del segundo mundo, la aparición de una red de ciudades mundiales, y la globalización de la producción cultural- ella continúa ejerciendo influencia en el imaginario" (Escobar, 2007, p. 29).

La concepción del turismo, asociada a esta ideología del desarrollo, se basa en una política económica sustentada en la introducción de nuevas actividades en zonas marginadas para hacerle frente a la pobreza (Organización Mundial del Turismo [OMT], 1999). Una mirada que ha predominado y se apoya en el turismo como un hecho netamente económico, impulsando el ingreso de inversores externos que promoverán el dinamizador del gasto del turista. 
Dentro de los múltiples cuestionamientos que ha sufrido este tipo de modelo de desarrollo turístico, podemos resaltar que no pudo resolver ninguno de los principales argumentos con los que se presenta a la "sociedad", tanto como fuente generadora de ingresos como de empleo. En economías de enclave, el monocultivo del turismo promueve la sustitución en muchos casos de actividades productivas que aseguren las condiciones de subsistencia de sus poblaciones locales, reemplazadas en cambio por la especulación inmobiliaria de la tierra y una economía especializada en los servicios, consolidando - en la mayoría de los casos - mayores niveles de pobreza y desocupación.

En ámbitos rurales, el turismo personifica la posible salida a las continuas crisis de las economías regionales, un medio a la mano y de supuestos beneficios ante la recesión e incluso retraimiento de las condiciones de una economía tradicional. Más aún, en estos momentos en que se debate la salida a la pandemia del Coronavirus y sus consecuencias sobre la economía mundial, el turismo sería una herramienta para resolver no solo la coyuntura que se presenta, sino las problemáticas estructurales.

Esta visión no considera las implicancias de la diferencia en la distribución de los ingresos económicos, reproduciendo los niveles de concentración y desigualdad sobre la población local. Además de los graves impactos ambientales sobre un espacio social, reconvertido en recurso a través de paradigmas que sostienen conceptos cada vez más cuestionados, como la "puesta en valor" de sus paisajes y cultura.

La realidad de las ciudades turísticas, fragmentadas y seccionadas social y espacialmente en "no lugares" y fracturadas por una "liminalidad" producida por la diferenciación económica y urbana, fracciona sus barrios y distintos sectores entre turísticos y no turísticos. Esta visión omite deliberadamente un enfoque más amplio e integral, que permita comprender y considerar las necesidades e impactos en las poblaciones locales o receptoras.

Para el caso del turismo, esta segmentación del territorio en turístico y no turístico es una realidad repetida y acentuada. Esta realidad incrementa la marginalidad en la periferia de las ciudades turísticas. Los principales actores afectados son aquellos que no tienen una relación directa con el turismo o su vínculo es lateral o circunstancial. El caso más emblemático de la situación descrita en la región, es la ciudad de San Carlos de Bariloche, el principal destino turístico de la Patagonia y uno de los más reconocidos de la Argentina.

Como indica Bonanno (2017), si recurrimos al antropólogo francés Marc Augé (1994) y al antropólogo escocés Víctor Turner (1988), ambos explicitan términos como "no lugar" o "liminalidad" respectivamente, para distinguir aquellos espacios de cambio, trasgresión e irracionalidad. Estos son sitios anónimos y rituales que ocupa el 
turista, quien muchas veces traspasa incluso las normas sociales, jurídicas y morales. "Augé denuncia que la industria turística vende el paraíso en países sumidos en la pobreza, las relaciones humanas entre locales y turistas son parodias que afianzan las desigualdades. El turista está inmerso en un juego liminal, fuera del tiempo y lugar" (Bonanno, 2017, p.5).

Hay innumerables ejemplos en los cuales el turismo se ha desarrollado con un modelo que promueve principalmente la maximización de la rentabilidad, bajo el formato de un turismo masificado que, como se ha sostenido, se puede denominar más apropiadamente como "extractivista", dentro de una lógica neoliberal que lo ha promovido a partir de la década de los años 90. En este sentido, Svampa y Viale (2014) advierten que la escala de los emprendimientos de tipo extractivistas, además de ser de gran envergadura, son inversiones que tratan de actividades capital-intensivas y no trabajo-intensivas, y los actores involucrados tienden a la concentración económica del tipo de grandes corporaciones transnacionales.

La aceptación —-tácita o explícita- de dicho "consenso" contribuye a instalar un nuevo escepticismo o ideología de la resignación que refuerza, en el límite, la "sensatez y razonabilidad" de un capitalismo progresista, imponiendo la idea de que no existirían otras alternativas al actual estilo de desarrollo extractivista. En consecuencia, todo discurso crítico u oposición radical terminaría por instalarse en el campo de la antimodernidad, de la negación del progreso o simplemente de la irracionalidad y el fundamentalismo. (Svampa y Viale, 2014, p.17)

La pandemia, y sus consecuencias, nos ofrece un espacio y un tiempo para repensar el desarrollo turístico, un debate necesario sobre el rol del Estado y la promoción de la actividad privada que estimula principalmente la radicación de grandes inversores en el sector servicios, en especial de origen extranjero, en lugar de promover los pequeños y medianos emprendimientos locales.

Estas racionalidades han encontrado en el turismo una base ideológica sólida para reforzar los pares de opuestos que han cruzado la historia de América Latina y de gran parte del mundo, y que todavía se siguen sustentando: dominador / dominados e inclusión / exclusión. 


\section{A modo de comentarios finales sobre la posibilidad de prácticas y modelos alternativos de un turismo solidario, comunitario y socialmente sustentable}

A nivel mundial, el aumento de los desplazamientos turísticos, hasta el 2019, seguía una clara tendencia ascendente de crecimiento económico medido por el PBI, especialmente hacia los destinos con políticas cambiarias favorables. La OMT indica que el sector turístico tiene una participación en el PBI entre un $3 \%$ y $4 \%$ después de los efectos de la crisis iniciada en septiembre de $2008^{6}$. Sin embargo, todo hace prever un notable decrecimiento del turismo, difícil de diagnosticar en su real incidencia y dimensión, a partir de 2020, como consecuencia de la pandemia de la Covid-19.

Esta suerte de freno, que ha detenido casi en su totalidad al turismo mundial, representa un momento para replantear los lineamientos que han marcado, a lo largo de estos últimos 70 años, el modelo de desarrollo en general y del turismo en particular. Es necesario comenzar a debatir alternativas a escala humana y local, de tipo participativo, comunitario y socioculturalmente sustentable.

Como ya hemos destacado en trabajos anteriores, entre las causas del fracaso de tantos planes con sus proyectos de desarrollo turístico, se destaca su centralismo demostrado en un proceso vertical, que va del centro a la periferia. Al igual que la escasa o nula adecuación al marco social y cultural de las poblaciones destinatarias, preocupados más por la sostenibilidad económica, ecológica y ambiental, que por la justicia social.

Al analizar el turismo desde un contexto espacial e histórico, teniendo en cuenta también la relación con comunidades rurales de ascendencia étnica, se lo puede comprender como un fenómeno social complejo debido a la multiplicidad de actores que intervienen en él, las relaciones de poder asimétricas y la conflictividad territorial ante la reproducción del capital desplegado por los sectores dominantes. En otras palabras, esta relación trata de expandir en toda su dimensión las estrategias que se han construido entre estos dos "mundos": uno sustentado sobre la base de una economía de subsistencia y teniendo como principio regulador el de reproducción de

6 "Las llegadas de turistas internacionales crecieron un 7,0 \% en 2017, el mayor aumento desde la crisis económica mundial de 2009 y muy por encima de la previsión a largo plazo de la OMT de $3,8 \%$ al año para el periodo de 2010 a 2020. Se registraron un total de 1.326 millones de llegadas de turistas internacionales en destinos de todo el mundo, en torno a 86 millones más que en 2016" (Organización Mundial del Turismo [омт], 2018 , p. 5). 
la unidad doméstica; y otro marcado por una actividad del sector terciario de servicios, sustentada bajo los parámetros de rentabilidad económica y calidad de la prestación.

En el caso del turismo, han surgido diversas modalidades adaptativas a las formas imperantes, tendientes a suavizar su impacto y promover una aceptación incondicional sin cuestionar el contenido ni sus estrategias. Designaciones más acordes con los tiempos que transcurren. Exponiendo un interés por el medio ambiente, han aparecido formatos denominados como "turismo ecológico, responsable o sustentable", revestidos de una supuesta dimensión social y utilizando preceptos como desarrollo local y participativo. Pero se ha comprobado, en diversas ocasiones, que son formatos que no han cuestionado el interior de un marco ideológico y político que determina una lógica de intervenciones en el territorio, sin relegar su orientación hacia el mercado. Tampoco resuelven los problemas por los que atraviesan los contextos rurales, reforzando la dominación y dependencia hacia formas externas de poder.

A pesar de sus buenas intenciones, estas propuestas continúan poniendo el acento en la búsqueda y formación de nuevos empresarios en la población local, quienes, mediante la capacitación y asesoramiento adecuado brindado por el propio Estado o a través de consultoras privadas, puedan reunir en un futuro mediato las condiciones requeridas para la reproducción del capital. En este nuevo contexto, el "emprendedurismo", adaptado a ambientes rurales y étnicos, trataría de fomentar productores reconvertidos en prestadores de servicios y actividades turísticas; una política que subsidie u otorgue créditos a los considerados más "aptos"; la competencia y el libre ejercicio del mercado, en un territorio con historia de solidaridad y trabajo cooperativo, a partir de una economía de carácter primaria relacionada con la tierra. En síntesis, "el territorio es un espacio construido socialmente de relaciones entre aspectos históricos y geográficos, procesos sociales e identitarios e intereses de los actores involucrados en la práctica turística" (Sousa, 2005, citado por Moscoso, 2012, p. 4).

En la segunda década del presente siglo es vital encontrar nuevos paradigmas de desarrollo que reemplacen a aquellos dominantes y que se han extendido a la ruralidad, entendida como un paisaje antropizado y convertido en un escenario turistificado, en lugar de un territorio culturalmente autónomo. Es necesario generar un turístico basado en una economía social campesina, que permita enfrentar enfrentar los embates del capitalismo neoliberal, cuya lógica, como hemos visto, comienza a consolidarse en ámbitos rurales o periurbanos.

Se hace indispensable generar alternativas productivas asociativas y participativas, implementadas a través de formas organizativas propias; como también economías basadas en la solidaridad y el trabajo sobre el capital. En este camino a desandar, 
se abren nuevas expectativas tendientes a respetar e incorporar en los proyectos de etnodesarrollo la cultura de las poblaciones destinatarias. En palabras de Bonfil, "la capacidad social de decisión sobre los recursos culturales, aquellos componentes de una cultura que deben ponerse en juego para identificar las necesidades, los problemas y las aspiraciones de la propia sociedad, e intentar satisfacerlas, resolverlas y cumplirlas" (Batalla, 1995, p. 468)

Para el turismo, esto representa un proceso de cambio, que involucra entenderlo a profundidad y desde una perspectiva social.

El análisis realizado muestra que, detrás de un escenario montado y especializado sobre la base de los recursos naturales (bosque, lagos, montañas) y culturales (cosmovisión mapuche: mitos y leyendas - pioneros migrantes: historia de esfuerzo y colonos), se ha desconocido una población residente que no participa directamente en el turismo, como tampoco en la vida social o política de las sociedades de frontera sobre las que se asentaron. Ya que el turismo es la base económica más importante de toda la región, esto implica que aquellos sectores más vulnerables o que no se contemplan dentro de las políticas turísticas de un destino, no tienen oportunidad de incorporarse a esta actividad en las actuales condiciones, y, si lo hacen, es a través de empleos no calificados, temporales y precarizados.

En la última década, de cara a los cambios en la sociedad que suponen la diversidad y la interculturalidad, el paso siguiente es construir propuestas turísticas que involucren a los propios pobladores y al grupo doméstico en los distintos proyectos de autogestión. Esto requiere el diseño y elaboración, en forma participativa y horizontal, de un modelo de desarrollo de un turismo que se posiciona desde una lógica que trata de promover la elaboración teórica y la puesta en práctica de formas de producción que se basen y tengan en cuenta la "dimensión cultural" del desarrollo. Esto significa generar las condiciones para que la población residente adquiera las herramientas para actuar en forma autónoma.

Para esto es indispensable la reflexión, al mismo tiempo que una mirada al interior de las unidades académicas que forman profesionales en turismo. En ese sentido, es inevitable replantear los planes de estudio en cuestiones relacionadas con la propia práctica profesional, dando origen a la elaboración de un marco teórico que sustente y de sentido al trabajo de campo que vincula un fenómeno social y económico.

Estos modelos alternativos de desarrollo requieren de profesionales ideológicamente comprometidos y que se posicionen como sujetos políticos e intelectuales, con valores puestos en juego en su labor técnica. El desarrollo productivo turístico, en poblaciones y comunidades rurales de base campesina y étnica, demanda un profesional con una sensibilidad social y una formación curricular y extracurricular 
en ciencias sociales. Este andamiaje le brindará al profesional un abordaje diferenciador, que le permita tener en cuenta la conformación de las estructuras sociales, territoriales y culturales, a partir de las cuales desarrolla su dinámica de trabajo y un permanente análisis crítico sobre las formas de intervención.

Esto supone la creación de un modelo que se apoye en las estructuras organizativas, sociales y productivas (autorreconocidas y preexistentes), en las cuales se sustenta la vida comunitaria. Requiere el diseño de propuestas que se sustenten en la integración comunitaria, mediante la cual los pobladores rurales tengan la posibilidad de incorporarse como prestadores turísticos de sus propios proyectos, tanto familiares como comunitarios, integrándose en forma complementaria con las otras actividades productivas tradicionales.

A priori o a posteriori, según se trate de un contenido simbólico intencionado desde el promotor del diseño espacial o como producto de la apropiación de los usuarios. Al parecer cuando es la propia comunidad quien decide y diseña el espacio, las categorías de acción transformación e identificación simbólica se condensan en un mismo acto de apropiación, capaz de construir por sí solo un nuevo espacio simbólico. (Berroeta y Rodríguez, 2010. p. 17)

El cambio se gesta con una corriente de pensamiento que puede comenzar a consolidarse en las actuales condiciones de la denominada pospandemia. Un tiempo y espacio propicio para su formulación, debido a la incertidumbre por la que está atravesando el turismo, en especial aquellas formas masivas que atraviesan por una crisis y que la pandemia solo ayudó a visibilizar.

\section{Referencias}

Acosta, A. (2011). Extractivismo y neoextractivismo: Dos caras de la misma maldición. En M. Lang y D. Mokrani (Comp.), Más allá del desarrollo (pp.83-120). Abya Yala.

Augé, M. (1994). Los "no lugares" Espacios del anonimato. Una antropología de la sobremodernidad. Gedisa.

Balazote, A. (2006). Winkas y mapuches: producción cultural y oferta turística en una aldea de montaña en Norpatagonia, Argentina. ILHA. Revista de Antropología. 8(1-2), 117-136. https:// doi.org/10.5007/\%25x 
Berroeta, H. y Rodríguez M. (2010). Una experiencia de participación comunitaria de regeneración del espacio público. Revista Electrónica de Psicología Política, 8(22), 1-26.

Bonanno, E. (2017). El niño explorador. De turistas y ficciones. Ponencia IX Congreso Argentino de Antropología Social. Noviembre de 2017, Misiones Argentina.

Bonfil, G. (1995) Etnodesarrollo: Sus premisas jurídicas, políticas y de organización. INAH/ INI.

Coraggio, J. (2007). Economía social, acción pública y política: hay vida después del neoliberalismo. Ciccus.

Díaz, R. (2002). Estrategias de ocupación y control del territorio del pueblo originario Mapuche: el caso del Parque Nacional Lanín desde una perspectiva histórica. [Documento base para el proyecto "Self-Sustaining Community Development in Comparative Perspective"]. Universidad de Texas Sured Indígena-Neuquén.

Escobar, A. (2007). La invención del Tercer Mundo. Construcción y deconstrucción del desarrollo. El perro y la rana.

Impemba, M. (2013). ¿Los Otros Invisibles? La cultura mapuche en el expansionismo turístico de San Martín de los Andes. (1. ${ }^{\text {a }}$ ed.). Ferreyra Editor.

Impemba, M. (2017). Transformaciones territoriales en contextos interétnicos: el desarrollo turístico en comunidades Mapuche del Sudoeste Neuquino. Revista GeoPantanal, 12(22), 105-120.

Impemba, M. y Maragliano, G. (2019). Turismo y territorios en transformación en comunidades mapuce del sur de la Provincia de Neuquén, Argentina. Revista Antropologías del Sur, 6(12), 225-240. https://doi.org/10.25074/rantros.v6i12.1156

Manzanal, M. (2010). Desarrollo, poder y dominación. Una reflexión en torno a la problemática del desarrollo rural en Argentina. El desarrollo y sus lógicas en disputa en territorios del norte argentino. Ciccus.

Maragliano, M. (2010, 3-6 de agosto). Comunicación y apropiación de los significados del territorio de las comunidades mapuche a partir de la actividad turística [Discurso principal]. VI Jornadas de Investigación en Antropología Social, Buenos Aires, Argentina. https://cetripunco.org/ wp-content/uploads/2015/09/PONENCIA-MARAGLIANO-VI-JIAS-GT6.pdf

Moscoso, F. (2012). La construcción social del territorio y su incidencia en la concepción del destino turístico [Ponencia]. En Jornadas de Turismo y Desarrollo Sostenible El papel de las comunidades locales, Universidad Nacional de La Plata, Argentina. 
Organización Mundial del Turismo (Омт). (2018). Panorama OMT del turismo internacional. UNWTO. https://doi.org/10.18111/9789284419890.

Organización Mundial del Turismo (OMT). (27 de diciembre de 1999). Código Ético Mundial para el Turismo. Adoptado por la Resolución A/RES/406 (XIII) de la decimotercera Asamblea General de la OMT. Santiago de Chile.

Svampa, M. y Viale, E. (2014). Mal desarrollo. La Argentina del extractivismo y el despojo. Katz.

Turner, V. (1988 [1969]). El proceso ritual. Estructura y antiestructura. Taurus.

Valverde, S. (2010). Seríamos el espejo de lo que es Villa Pehuenia: Análisis comparativo-regional de los conflictos territoriales del pueblo mapuche en áreas turísticas de la provincia de Neuquén. Runa, XXX(1), 31-48.

Viola, A. (2000). La crisis del desarrollismo y el surgimiento de la antropología del desarrollo. En A. Viola (Comp.) Antropología del desarrollo: Teorías y estudios etnográficos en América Latina. Paidós. 